\title{
PAPER
}

\section{Quantitative MRI findings and cognitive impairment among community dwelling elderly subjects}

\author{
H Koga, T Yuzuriha, H Yao, K Endo, S Hiejima, Y Takashima, F Sadanaga, \\ T Matsumoto, A Uchino, K Ogomori, A Ichimiya, H Uchimura, N Tashiro
}

See end of article for authors' affiliations

....................

Correspondence to: Dr H Koga, Department of Neuropsychiatry, Faculty of Medicine, Kyushu

University Hospital,

Maidashi, Fukuoka

812-8582, Japan:

kogah@

npsych.med.kyushu-u.ac.jp

Received

1 February 2001

In revised form 2 July 2001

Accepted 6 August 2001

\begin{abstract}
Objectives: To study the factors which influence cognitive impairment among elderly subjects living in a local community, based on both MRI and clinical findings, to further elucidate the causes of dementia, and also to help develop strategies for its prevention.

Methods: Cranial MRI and other medical examinations were performed on non-demented elderly subjects who resided in one rural community. A total of 254 subjects aged from 60 to 91 years of age, with a mean age of 73.9 (SD 6.8) were examined. The mini mental state examination (MMSE) was used to identify cognitive impairment. White matter lesions and cerebral atrophy on MR images were measured quantitatively. A multivariate analysis was also performed with the existence of cognitive impairment as the dependent variable, and the MRI findings and clinical observations were used as the independent variables.

Results: Cognitive impairment was present in 46 subjects (18.1\%). They were older, had a lower educational level, and more frequent hypertension compared with those without cognitive impairment. The packed cell volume was lower in the impaired group. In addition, their MRI findings showed significantly larger quantities of white matter lesions and cerebral atrophy, as well as more infarcts. A logistic regression analysis demonstrated a significant relation among such factors as white matter lesions (odds ratio (OR) 1.575, 95\% confidence interval (95\% Cl) 1.123-2.208), cerebral atrophy (OR 0.761, 95\% Cl 0.587-0.987), and lower education (OR $0.682,95 \% \mathrm{Cl} 0.544-0.855$ ) for subjects with a cognitive impairment.

Conclusions: White matter lesions and cerebral atrophy are factors which induce a cognitive impairment in community dwelling elderly subjects without dementia. It is important to carefully watch for any abnormalities in these factors, and to perform cohort studies to check for the above risk factors, to both prevent and make an early diagnosis of dementia.
\end{abstract}

$\mathrm{E}$ lucidating the causes of dementia as well as making an early diagnosis, and developing strategies to prevent dementia are matters of extreme urgency in our aging society. So far several reports have been published on large scale examinations of the general population to investigate the course of dementia before and after its onset. ${ }^{1-6}$ There are also many reports about the influence of certain specific risk factors, such as white matter lesions, silent cerebral infarction, and other risk factors related to cognitive function. However, there have been few comprehensive studies which focus on cognitive impairment and the factors which influence them, based on both clinical observation and image examinations. ${ }^{78}$

In the present study, we performed cranial MRI and other procedures in elderly subjects who lead a normal life at home and investigated the factors influencing cognitive function based on a multivariate analysis. In particular, abnormal findings on MRI such as white matter lesions and cerebral atrophy were measured quantitatively. We herein report our findings which led to the conclusion that abnormal findings on MR images closely reflect a subtle cognitive effect even in nondemented subjects living in a local community.

\section{SUBJECTS AND METHODS}

Between June 1997 and November 1999, we examined 254 subjects aged 60 to 91 years old, living in the rural community of Sefuri village, Saga, Japan (the total population of the village numbered 1938 as of November 1999). All subjects were volunteers recruited from a local senior citizens' centre. The subjects comprised 69 men and 185 women, with a mean age of 73.9 (SD 6.8) years and a mean educational achievement of 8.5 (SD 1.8) years in this study. The participation rate in the study was 38\% for those aged 60 years or older. Any persons with chronic intracranial illnesses including cerebrovascular disease, psychiatric disorders, or a history of head trauma were excluded. All subjects were literate, living independently without any apparent dementia, at home in this community. Cranial MRI was performed on all subjects, and a patient history, general haematology tests, and biochemistry tests were also performed to evaluate any risk factors for cerebrovascular diseases such as hypertension, diabetes mellitus, and hyperlipidaemia. Blood pressure was measured in the sitting position by the standard cuff method. For the neurological examination, the presence of a Barré sign, asymmetric deep tendon reflexes, and Babinski's sign were recorded on each side. Left ventricular hypertrophy, ST depression, or atrial fibrillation were registered on 12 lead ECG recordings. The cognitive function was assessed in a battery of neuropsychological tests - the mini mental state examination (MMSE). ${ }^{9}$ The mean MMSE score in this study was 26.0 (SD 3.3) points. A few subjects had lower scores in the MMSE test, and some of subjects labelled as "cognitive impairment" might have had mild dementia. However, they could still care for themselves, and no subject had any obvious dementia that fulfilled the DSM-IV diagnostic criteria. ${ }^{10}$ All subjects were stratified into two groups based on the severity of cognitive

Abbreviations: MMSE, mini mental state examination; FLAIR, fluid attenuated inversion recovery; WMLs, white matter lesions 

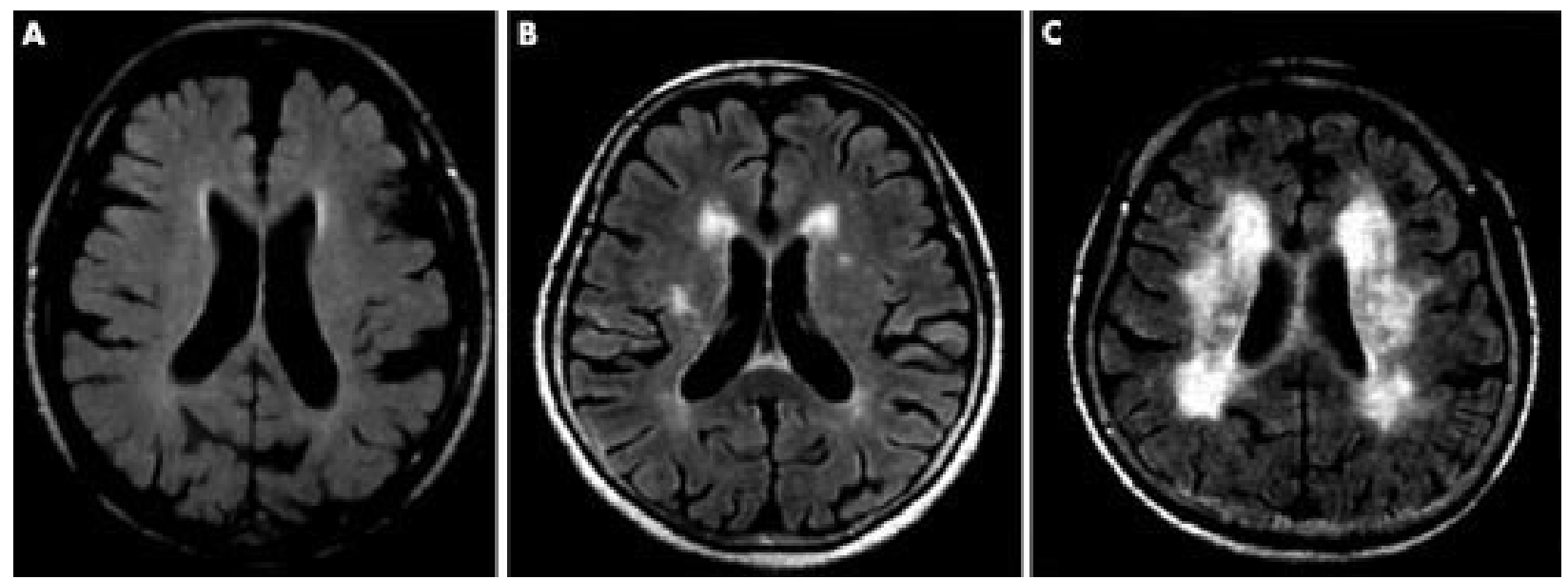

Figure 1 Example of quantitative measurement of \% WMLs of axial FLAIR-density (TR/TI/TE 5800/1700/110 ms) MRI images. The percentages of patients were $56.7 \%, 33.5 \%$, and $9.8 \%$ in each of the three categories represented in (A), (B), and (C), respectively. (A) An 80 year old subject with \%WMLs=0.9\% (corresponding to grade 0 of Fazekas's classification). (B) A 66 year old subject with \%WMLs=7.8\% (corresponding to grade 1 of Fazekas's classification). (C) An 81 year old subject with \%WMLs=23.6\% (corresponding to grades 2 and 3 of Fazekas's classification).

impairment, as defined by MMSE score less than $24 .{ }^{11-15}$ Consequently, 46 (18.1\%) subjects were defined as having a cognitive impairment.

Cranial MRI was performed on a $1.0 \mathrm{~T}$ superconducting magnet (MAGNEX a, Shimadzu, Kyoto, Japan) using the spin echo technique and fluid attenuated inversion recovery (FLAIR) sequences. Transverse Tl weighted (TR/TE 380/14 $\mathrm{ms}$ ), T2 weighted (TR/TE 3750/1 $10 \mathrm{~ms}$ ), and FLAIR (TR/TI/TE $5800 / 1700 / 110 \mathrm{~ms}$ ) images were obtained with a slice thickness of $8 \mathrm{~mm}$ separated by a $2 \mathrm{~mm}$ interscan gap. The MRI data were modified from $256 \times 256$ pixels to $512 \times 512$ pixels, and then were transferred from the MRI unit to a Macintosh computer. The area of white matter lesions and the brain volume was measured quantitatively on one slice using a computer assisted processing system (NIH Image version 1.61). White matter lesions were defined as high signal intensity areas on $\mathrm{T} 2$ weighted images but isointense with normal brain parenchyma on Tl weighted images. All measurements were performed on FLAIR images obtained at 2 slices above the level of the pineal body. The area of white matter lesions was quantitatively measured using a semiautomatic method to count the pixels with a given intensity. To correct for individual differences in head size on the measurement of white matter lesions (WMLs), they were calculated as a percentage of the total intracranial volume and defined as the \%WMLs. Using the same slice level as that for the measurement of white matter lesions, the area of the cerebral parenchyma was quantified on $\mathrm{T} 2$ images and was divided by the area inside the skull to calculate the \% brain value (\%Brain), which was used as an index of cerebral atrophy. Cerebral infarcts were defined qualitatively as lesions with an abnormal signal in vascular distribution and no mass effects, and were defined as low signal intensity areas on the $\mathrm{Tl}$ weighted images and high signal intensity areas on the T2 weighted images and their sizes were $5 \mathrm{~mm}$ or larger. The presence or absence of infarcts and the number of infarcts in the whole brain were determined qualitatively.

Table 1 Clinical and neuroradiological features of patients with or without cognitive impairment

\begin{tabular}{|c|c|c|c|}
\hline & $\begin{array}{l}\text { Cognitive } \\
\text { impairment }(+)(n=46)\end{array}$ & $\begin{array}{l}\text { Cognitive } \\
\text { impairment }(-)(n=208)\end{array}$ & $\mathrm{p}$ Value \\
\hline Age (y) & $78.0(6.3)$ & $72.9(6.6)$ & $<0.0001$ \\
\hline $\operatorname{Sex}(M / F)$ & $11 / 35$ & $58 / 150$ & 0.5837 \\
\hline Educational level (y) & $7.4(1.3)$ & $8.7(1.9)$ & $<0.0001$ \\
\hline History of hypertension (+) & $24(52) \%$ & $68(33) \%$ & 0.0140 \\
\hline History of diabetes mellitus $(+)$ & $3(7) \%$ & $10(5) \%$ & 0.6331 \\
\hline Systolic blood pressure $(\mathrm{mm} \mathrm{Hg})$ & $159.0(26.3)$ & $144.6(23.0)$ & 0.0002 \\
\hline Diastolic blood pressure $(\mathrm{mm} \mathrm{Hg})$ & $76.9(9.9)$ & $75.7(10.3)$ & 0.4953 \\
\hline \multicolumn{4}{|l|}{ Blood chemistry: } \\
\hline Packed cell volume & $0.36(0.04)$ & $0.39(0.04)$ & 0.0012 \\
\hline Albumin (g/l) & $42.4(3.4)$ & $43.0(2.7)$ & 0.1923 \\
\hline Fasting blood glucose $(\mathrm{mmol} / \mathrm{l})$ & $5.32(1.20)$ & $5.22(1.28)$ & 0.6353 \\
\hline Total cholesterol $(\mathrm{mmol} / \mathrm{I})$ & $4.89(1.17)$ & $5.07(0.83)$ & 0.2130 \\
\hline HDL cholesterol (mmol/l) & $1.45(0.30)$ & $1.51(0.37)$ & 0.2800 \\
\hline Abnormal neurological signs (+) & $4(9) \%$ & $12(6) \%$ & 0.4597 \\
\hline Abnormal ECG $(+)^{*}$ & $11(24) \%$ & $32(15) \%$ & 0.1628 \\
\hline \multicolumn{4}{|l|}{ MRI findings: } \\
\hline \%WML (\%) & $8.25(4.40)$ & $5.03(4.25)$ & $<0.0001$ \\
\hline$\%$ Brain $(\%)$ & $79.0(5.8)$ & $83.1(6.3)$ & $<0.0001$ \\
\hline Cerebral infarction $(+)$ & $16(35) \%$ & $38(18) \%$ & 0.0130 \\
\hline (No per case) & $1.65(1.04)$ & $1.65(1.01)$ & 0.0302 \\
\hline
\end{tabular}


Table 2 Logistic regression analysis of factors affecting cognitive impairment

\begin{tabular}{llllll}
\hline Variables & B & SE & p Value & OR & $95 \% \mathrm{Cl}$ \\
\hline \%WMLs (/5\%) & 0.0908 & 0.0345 & 0.0085 & 1.575 & 1.123 to 2.208 \\
$\%$ Brain (/5\%) & -0.0546 & 0.0265 & 0.0392 & 0.761 & 0.587 to 0.987 \\
Education (/y) & -0.3824 & 0.1152 & 0.0009 & 0.682 & 0.544 to 0.855 \\
\hline B, coefficient; SE, standard error; OR, odds ratio.
\end{tabular}

All values are given as mean (SD). We used the SPSS software package (SPSS Advanced Statistics ${ }^{\mathrm{TM}}$ version 6.1, SPSS Inc, Chicago, IL, USA) for the statistical analysis. A univariate analysis was performed with a $t$ test for continuous variables and the $\chi^{2}$ test for categorical variables. A linear regression was performed with Spearman's rank correlation. Multivariate analyses were done using a logistic regression model to identify any factors predictive of cognitive impairment on the entire sample of 254 subjects. We used the forward stepwise method of logistic analysis. We chose the variables for entry into the multivariate analysis based on the clinical and neuroradiological findings with values of $\mathrm{p}<0.05$ considered significant after univariate testing.

\section{RESULTS}

The volume of \%WMLs ranged from $0.37 \%$ to $29.7 \%$ of the intracranial area with a mean of $5.61(4.44) \%$. Figure 1 shows examples of the quantitative measurement of \%WMLs of axial FLAIR density MRI images. The volume of the \%Brain ranged from $66.1 \%$ to $94.6 \%$ of the intracranial volume with a mean of $82.3(6.4) \%$. Definite brain infarcts were seen in 54 subjects $(21.3 \%)$ with a mean number of 1.65 (1.01) infarcts. The MRI and clinical findings were analyzed to detect any factors influencing the cognitive function of the subjects.

Table 1 shows the comparisons of the independent variables between the subjects with and without cognitive impairment as defined by the MMSE cognitive scale. Subjects with cognitive impairment, who scored below 24 points on the MMSE scale, were significantly older (78.0 years $v 72.9$ years, $\mathrm{p}<0.0001)$, less educated $(7.4$ years $v 8.7$ years, $\mathrm{p}<0.0001)$, more likely to have cerebral infarction on MRI ( $35 \% v 18 \%$, $\mathrm{p}=0.013)$, a history of hypertension $(52 \% v 33 \%, \mathrm{p}=0.014)$, lower packed cell volume $(0.36 \vee 0.39, \mathrm{p}=0.0012)$, and higher systolic blood pressure ( $159 \mathrm{~mm} \mathrm{Hg} v 145 \mathrm{~mm} \mathrm{Hg}$ ). The mean \%WMLs volume for subjects with cognitive impairment was $8.25(4.40) \%$ compared with $5.03(4.25) \%$ for the subjects without cognitive impairment $(\mathrm{p}<0.0001)$. The mean \%Brain

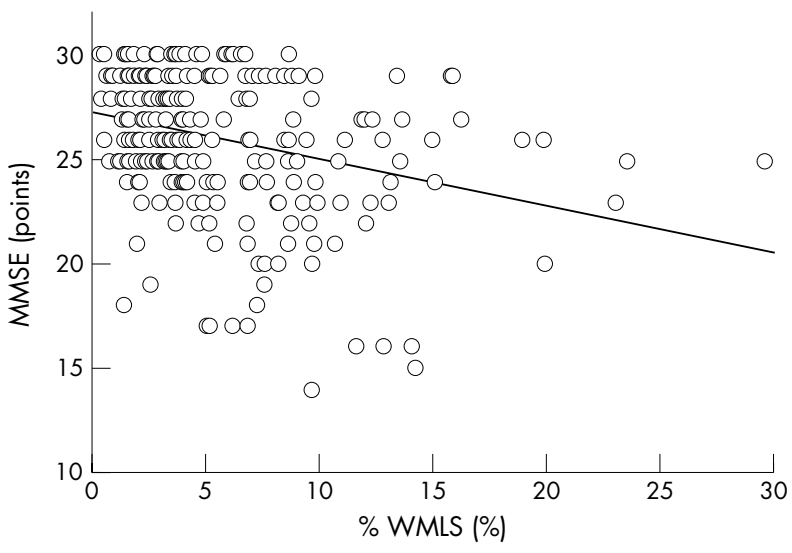

Figure 2 Correlation between \%WMLs (white matter lesions) and cognitive function (MMSE score). A linear regression was performed with Spearman's rank correlation and the regression line is shown. Coefficient of association $=-0.297, p$ value $<0.0001$.

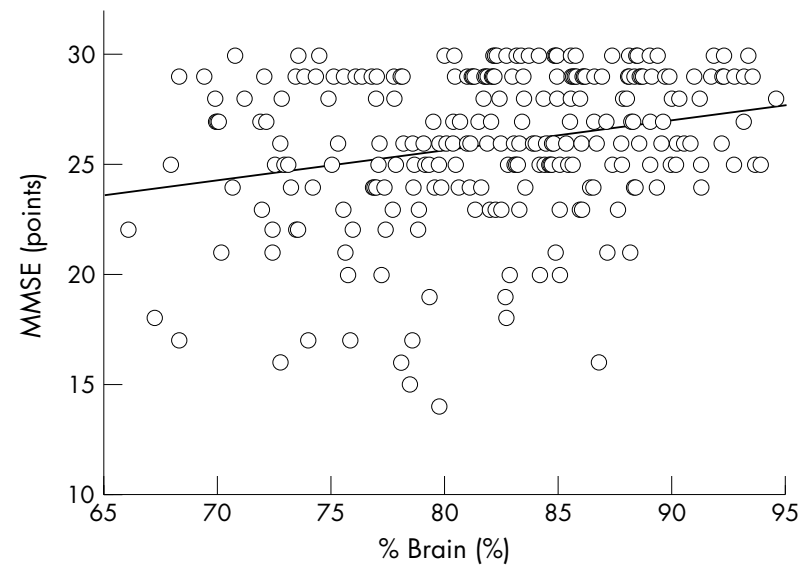

Figure 3 Correlation between \%Brain and cognitive function (MMSE score). A linear regression was performed with Spearman's rank correlation and the regression line is shown. Coefficient of association $=0.258, \mathrm{p}$ value $=0.0002$.

volume for the subjects with cognitive impairment was 79.0 $(5.8) \%$ compared with $83.1(6.3) \%$ for the subjects without cognitive impairment $(\mathrm{p}<0.0001)$.

Table 2 shows the results of a multivariate analysis between cognitive impairment and the MRI and clinical findings. The logistic analysis included factors which were significant based on a univariate analysis as variables in the models. Within the multivariate models cognitive impairment was related to the \%WMLs (odds ratio (OR) 1.575, 95\% confidence interval (95\%CI) 1.123-2.208), to the \%Brain (OR 0.761, 95\%CI 0.5870.987 ), and to the educational level (OR 0.682, 95\%CI $0.544-0.855)$. A statistical analysis was done for an increase in educational background by 1 year, as well as for the \%WMLs and the \%Brain by $5.0 \%$.

A multivariate analysis of the \%WMLs and the \%Brain showed an influence on cognitive impairment, and a significant correlation was noted between these parameters and the cognitive function, as shown in figures 2 and 3.

\section{DISCUSSION}

In the present study, we used a quantitative MRI method to investigate the factors affecting the cognitive function of elderly people who were leading normal lives at home, and concluded that white matter lesions, cerebral atrophy, and educational background had an important influence on cognitive impairment. Several studies of the general population have previously focused on the prevalence of dementia and the factors affecting its onset. ${ }^{1-6} 16{ }^{17}$ However, most of these reports tend to focus on particular lesions including WMLs and silent cerebral infarction, and thus study the frequencies and risk factors of such lesions, or relate such lesions to cognitive impairment. Investigating the MRI findings in relation to cognitive impairment in elderly subjects is considered to be important because such data can be used for both prophylaxis and early detection. But only a few reports in the past have attempted to discuss a wide range of factors which influence cognitive troubles in the general population. ${ }^{78}$ Among these studies, Kuller et al performed a large scale resident study and reported that factors influencing cognitive impairment were cerebral atrophy, white matter lesions, and cerebral infarction on MRI, ApoE4 genotype, age, educational background, and race. They qualitatively assessed abnormalities on MRI images, ${ }^{18}$ whereas we analyzed the quantitative data. They also studied elderly subjects under various conditions, ${ }^{19}$ whereas we excluded subjects with intracranial lesions, cerebrovascular accidents, or dementia, and instead studied a relatively homogeneous group of healthy elderly subjects. 
White matter lesions have been extensively investigated regarding cognitive impairment. Many studies ${ }^{17}{ }^{20-24}$ have used qualitative methods for evaluating the size or severity of white matter lesions, but quantitative data have also been increasingly reported..$^{25-30}$ Because qualitative methods provide rather obscure criteria for evaluating the severity of white matter lesions, we employed a quantitative method. In our preparatory research using the qualitative method, the relation between WMLs and cognitive impairment has already been described. ${ }^{31}$ Regarding the role of white matter lesions in cognitive impairment, an association between such lesions and cognitive impairment in normal elderly subjects has been reported, ${ }^{24-27}{ }^{32}$ although the absence of any relation with cognitive function has also been reported. $.^{22}{ }^{23} 33-35$ DeCarli et al ${ }^{26}$ counted the number of pixels on the MR images to quantitatively define the volume of WMLs in their study of normal subjects. They evaluated the subjects by whole brain volume, and therefore, the \%WMLs was smaller than in our results, and they defined $0.5 \%$ or less to be normal. Their results show the volume of WMLs to be significantly related to cognitive impairment, which reflects the level of frontal lobe function. Wahlund et al ${ }^{28}$ quantitatively analyzed the WMLs of normal subjects and made a comparison with the MMSE results. They reported that the MMSE scores and volumes of WMLs were closely correlated. The above mentioned diversity in the results of research on the influence of WMLs on cognitive functions is partly due to the differences in the research methods and the contents of psychological tests, in addition to differences between subjects.

Our present results demonstrated no significant relation between brain infarction and cognitive impairment. The cerebral infarction shown on MRI was mostly silent and small in size in this study. Some reports ${ }^{13}{ }^{36-40}$ have already well described the relation between silent brain infarctions and cognitive impairment. Regarding the role of silent cerebral infarctions in cognitive impairment, no association between such lesions and cognitive impairment in normal elderly subjects has previously been reported, ${ }^{71}$ although the absence of any relation with cognitive function has also been reported. ${ }^{82}{ }^{43}$ In our previous study, ${ }^{44}$ in which we used CT, of about 200 community dwelling elderly subjects, we found that problems of mental functions were influenced by aging, cerebral infarction, and WMLs. The absence of any association between cerebral infarction and cognitive impairment in the present study may be attributable to the following factors: (1) MRI detected even very small infarcts and (2) those with known cerebrovascular disease were excluded, so the subjects rarely had infarcts that affected critical regions.

A substantial degree of cerebral atrophy corresponds to the development of cognitive impairment, according to the findings of many studies on degenerative dementia. ${ }^{45-48}$ Some other studies on normal subjects ${ }^{79}{ }^{50}$ have made similar conclusions. Previous studies have also quantified the extent of cerebral atrophy. ${ }^{46-48} 51-55$ The cerebral atrophy that occurs in degenerative dementia is thought to differ from that in normal elderly people both regarding its aetiology and its clinical significance. The present study showed that cerebral atrophy had a slight influence on cognitive impairment. However, further studies are required to both clarify the mechanism by which cerebral atrophy plays a part in cognitive impairment in independent elderly people, as well as to identify the factors responsible for cerebral atrophy.

Educational background is thought to affect the results of the MMSE, ${ }^{756}$ which was used in this study. In fact, a strong influence of education was found in our study. The MMSE is probably the most widely used rating scale for a simple assessment of cognitive function in elderly subjects. ${ }^{9}$ A score of 23 or less is commonly used to reflect cognitive impairment when the issue is case detection. ${ }^{11-15}$ However, the MMSE score dose not reflect the cognitive function alone. Uhlmann et $\mathrm{l}^{57}$ have suggested that the cut off point of the MMSE should be adjusted according to the subject's educational background. On the other hand, some authors ${ }^{53} 55$ have stated that there is an inverse relation between educational background and cerebral atrophy which prevents cognitive impairment, although others have reported ${ }^{59-61}$ that low educational background is related to the risk of Alzheimer's disease. The educational background is greatly dependent on the environment during childhood, and therefore some researchers also consider that the childhood environment may influence future cognitive impairment. For the prevention and early detection of dementia, we therefore should discuss how to improve the educational level of the general population.

In conclusion, the present cross sectional study showed cognitive impairment in non-demented elderly subjects to be related to the educational level, the presence of WMLs, and brain atrophy. In the future, longitudinal studies are expected to clarify the risk factors or early findings of cognitive decline that can potentially be used for the early detection and prevention of dementia.

\section{ACKNOWLEDGEMENTS}

We are grateful to Dr A Nohtomi for his advice in writing this paper, $\mathrm{T}$ Yamanaka, for his advice on the statistical analyses, $\mathrm{T}$ Muto and $\mathrm{T}$ Wada for their assistance with the laboratory assays, and M Saito for technical assistance with the MRI.

\section{Authors' affiliations}

H Koga, K Ogomori, N Tashiro, Department of Neuropsychiatry, Faculty of Medicine, Kyushu University Hospital, Maidashi, Fukuoka 812-8582, Japan

T Yuzuriha, H Yao, K Endo, S Hiejima, Y Takashima, F Sadanaga,

T Matsumoto, H Uchimura, Center for Emotional and Behavioral

Disorders, Hizen National Hospital, Japan

A Ichimiya, Institute of Health Science, Kyushu University, Japan

A Uchino, Department of Radiology, Saga Medical College, Japan

\section{REFERENCES}

1 Breteler MMB, van Swieten JC, Bots ML, et al. Cerebral white matter lesions, vascular risk factors, and cognitive function in a population-based study: the Rotterdam Study. Neurology $1994: 44: 1246-52$

2 Fratiglioni L, Grut $M$, Forsell Y, et al. Prevalence of Alzheimer's disease and other dementias in an elderly urban population: relationship with age, sex, and education. Neurology 1991;41:1886-92.

3 Dartigues JF, Gagnon M, Mazaux JM, et al. Occupation during life and memory performance in nondemented French elderly community residents. Neurology 1992;42:1697-701.

4 Beard CM, Kokmen E, Offord KP, et al. Lack of association between Alzheimer's disease and education, occupation, marital status, or living arrangement. Neurology 1992:42:2063-8.

5 Ott A, Breteler MMB, van Harskamp F, et al. Prevalence of Alzheimer's disease and vascular dementia: association with education: the Rotterdam study. BM 1995;310:970-3.

6 Hébert R, Brayne C. Epidemiology of vascular dementia. Neuroepidemiology 1995;14:240-57.

7 Kuller LH, Shemanski L, Manolio T, et al. Relationship between ApoE, MRI findings, and cognitive function in the cardiovascular health study. Stroke 1998;29:388-98.

8 Matsubayashi K, Shimada K, Kawamoto A, et al. Incidental brain lesions on magnetic resonance imaging and neurobehavioral functions in the apparently healthy elderly. Stroke 1992;23:175-80.

9 Folstein MF, Folstein SE, McHugh PR. Mini-mental state: a practical method for grading the cognitive state of patients for the clinician. $J$ Psychiatr Res 1975;12:189-98.

10 American Psychiatric Association. Diagnostic and statistical manual of mental disorders. 4th ed. Washington, DC: American Psychiatric Association. 1994.

11 Braekhus A, Laake K, Engedal K. A low, normal score on the mini-mental state examination predicts development of dementia after three years. J Am Geriatr Soc 1995:43:656-61.

12 Barker A, Jones R, Jennison C. A prevalence study of age-associated memory impairment. Br J Psychiatry 1995;167:642-8.

13 Zhu L, Fratiglioni L, Guo Z, et al. Association of stroke with dementia, cognitive impairment, and functional disability in the very old; a population-based study. Stroke 1998:29:2094-9.

14 Celsis P, Agniel A, Cardebat D, et al. Age related cognitive decline: a clinical entity? A longitudinal study of cerebral blood flow and memory performance. J Neurol Neurosurg Psychiatry 1997;62:601-8.

15 Schmand B, Jonker C, Geerlings M, et al. Subjective memory complaints in the elderly: depressive symptoms and future dementia. $\mathrm{Br} J$ Psychiatry 1997;171:373-6. 
16 Ricci S, Celani MG, Rosa FL, et al. Silent brain infarctions in patients with first-ever stroke. A community-based study in Umbria, Italy. Stroke 1993;24:647-51.

17 Jørgensen HS, Nakayama H, Raaschou $\mathrm{HO}$, et al. Silent infarction in acute stroke patients. Prevalence, localization, risk factors, and clinical significance: the Copenhagen stroke study. Stroke 1994;25:97-104.

18 Bryan RN, Manolio TA, Schertz LD, et al. A method for using MR to evaluate the effects of cardiovascular disease on the brain: the cardiovascular health study. ANNR Am J Neuroradiol 1994;15:1625-33.

19 Fried LP, Borhani NO, Enright $P$, et al. The cardiovascular health study: design and rationale. Ann Epidemiol 1991;1:263-76.

20 Fazekas $F$, Chawluk JB, Alavi A, et al. MR signal abnormalities at $1.5 \mathrm{~T}$ in Alzheimer's dementia and normal aging. AJNR Am J Neuroradiol 1987;8:421-6.

21 Breteler MMB, van Amerongen NM, van Swieten JC, et al. Cognitive correlates of ventricular enlargement and cerebral white matter lesions on magnetic resonance imaging. the Rotterdam study. Stroke 1994;25: $1109-15$

22 Hendrie HC, Farlow MR, Austrom MG, et al. Foci of increased T2 signal intensity on brain MR scans of healthy elderly subjects. ANNR Am J Neuroradiol 1989;10:703-7.

23 Hunt AL, Orrison WW, Yeo RA, et al. Clinical significance of MRI white matter lesions in the elderly. Neurology 1989;39:1470-4.

24 Ylikoski R, Ylikoski A, Erkinjuntti T, et al. White matter changes in healthy elderly persons correlate with attention and speed of mental processing. Arch Neurol 1993;50:818-24.

25 Schmidt R, Fazekas F, Offenbacher H, et al. Neuropsychologic correlates of MRI white matter hyperintensities: a study of 150 normal volunteers. Neurology 1993;43:2490-4.

26 DeCarli C, Murphy DGM, Tranh M, et al. The effect of white matter hyperintensity volume on brain structure, cognitive performance, and cerebral metabolism of glucose in 51 healthy adults. Neurology 1995; 45:2077-84

27 Boone KB, Miller BL, Lesser IM, et al. Neuropsychological correlates of white-matter lesions in healthy elderly subjects. a threshold effect. Arch Neurol 1992;49:549-54

28 Wahlund LO, Andersson-Lundman G, Julin P, et al. Quantitative estimation of brain white matter abnormalities in elderly subjects using magnetic resonance imaging. Magn Reson Imaging 1992;10:859-65.

29 Fazekas $F$, Kapeller $P$, Schmidt R, et al. The relation of cerebral magnetic resonance signal hyperintensities to Alzheimer's disease. J Neurol Sci 1996;142:121-5.

30 Tanabe JL, Amend D, Schuff N, et al. Tissue segmentation of the brain in Alzheimer disease. AJNR Am J Neuroradiol 1997;18:1 15-23.

31 Yao H, Yuzuriha T, Koga H, et al. Decreased plasma tryptophan associated with deep white matter lesions in elderly subjects. I Neurol Neurosurg Psychiatry 1999;66:100-3

32 Steingart A, Hachinski VC, Lau C, et al. Cognitive and neurologic findings in subjects with diffuse white matter lucencies on computed tomographic scan (leuko-araiosis). Arch Neurol 1987:44:32-5.

33 Tupler LA, Coffey CE, Logue PE, et al. Neuropsychological importance of subcortical white matter hyperintensity. Arch Neurol 1992;49:1248-52

34 Fein G, van Dyke C, Davenport L, et al. Preservation of normal cognitive functioning in elderly subjects with extensive white-matter lesions of long duration. Arch Gen Psychiatry 1990;47:220-3.

35 Wahlund LO, Almkvist O, Basun $\mathrm{H}$, et al. MRI in successful aging, a 5 year follow up study from the 8th to 9th decade of life. Magn Reson Imaging 1996;14:601-8.

36 Kwan LT, Reed BR, Eberling JL, et al. Effects of subcortical cerebral infarction on cortical glucose metabolism and cognitive function. Arch Neurol 1999;56:809-14

37 Breteler MMB, Claus JJ, Grobbee DE, et al. Cardiovascular disease and distribution of cognitive function in elderly people: the Rotterdam study. BM 1994;308:1604-8.

38 Price TR, Manolio TA, Kronmal RA, et al. Silent brain infarction on magnetic resonance imaging and neurological abnormalities in community dwelling older adults: the cardiovascular health study. Stroke 1997;28:1158-64.
39 Fushimi $\mathbf{H}$, Inoue T, Yamada $Y$, et al. Asymptomatic lacunes and their relationship to intellectual disturbances. Intern Med 1994;33:317-20.

40 Yoshitake T, Kiyohara Y, Kato I, et al. Incidence and risk factors of vascular dementia and Alzheimer's disease in a defined elderly Japanese population; the Hisayama study. Neurology 1995;45:1161-8.

41 Longstreth WT Jr. Brain abnormalities in the elderly: frequency and predictors in the United States (the cardiovascular health study). for the Cardiovascular Health Study Collaborative Research Group. J Neural Transm Suppl 1998;53:9-16.

42 Chodosh EH, Foulkes MA, Kase CS, et al. Silent stroke in the NINCDS stroke data bank. Neurology 1988;38:1674-9.

43 Snowdon DA, Greiner $\mathrm{LH}$, Mortimer JA, et al. Brain infarction and the clinical expression of Alzheimer disease: the Nun study. JAMA 1997;277:813-17.

44 Koga $\mathbf{H}$, Kondo A, Yao $\mathrm{H}$, et al. Clinical features and white matter lesions in community dwelling elderly individuals: the consequence of examination for computed tomography. Japanese Journal of Geriatric Psychiatry 2000;1 1:1035-42. (In Japanese.)

45 Fox NC, Scahill RI, Crum WR, et al. Correlation between rates of brain atrophy and cognitive decline in AD. Neurology 1999;52:1687-9.

46 Pearlson GD, Harris GJ, Powers RE, et al. Quantitative changes in mesial temporal volume, regional cerebral blood flow, and cognition in Alzheimer's disease. Arch Gen Psychiatry 1992;49:402-8.

47 Murphy DGM, DeCarli CD, Daly E, et al. Volumetric magnetic resonance imaging in men with dementia of the Alzheimer type: correlations with disease severity. Biol Psychiatry 1993;34:612-21.

48 Mizuno K, Wakai M, Takeda A, et al. Medial temporal atrophy and memory impairment in early stage of Alzheimer's disease: an MRI volumetric and memory assessment study. J Neurol Sci 2000; 173: 18-24

49 Raz N, Briggs SD, Marks W, et al. Age related deficits in generation and manipulation of mental images: Il. The role of dorsolateral prefrontal cortex. Psychol Aging 1999;14:436-44.

50 Raz N, Gunning-Dixon FM, Head D, et al. Neuroanatomical correlates of cognitive aging: evidence from structural magnetic resonance imaging. Neuropsychology 1998;12:95-114.

51 Strassburger TL, Lee HC, Daly EM, et al. Interactive effects of age and hypertension on volumes of brain structures. Stroke 1997;28:1410-17.

52 DeCarli C, Murphy DGM, Gillette JA, et al. Lack of age related differences in temporal lobe volume of very healthy adults. ANNR Am J Neuroradiol 1994;15:689-96.

53 Coffey CE, Saxton JA, Ratcliff G, et al. Relation of education to brain size in normal aging: implications for the reserve hypothesis. Neurology 1999;53:189-96.

54 Mori E, Hirono N, Yamashita H, et al. Premorbid brain size as a determinant of reserve capacity against intellectual decline in Alzheimer's disease. Am J Psychiatry 1997:154:18-24.

55 Kidron D, Black SE, Stanchev P, et al. Quantitative MR volumetry in Alzheimer's disease: topographic markers and the effects of sex and education. Neurology 1997;49:1504-12.

56 Pálsson S, Aevarsson Ó, Skoog I, et al. Depression, cerebral atrophy, cognitive performance and incidence of dementia: population study of 85 year olds. Br J Psychiatry 1999; 174:249-53.

57 Uhlmann RF, Larson EB. Effect of education on the mini-mental state examination as a screening test for dementia. J Am Geriatr Assoc 1991;39:876-80.

58 Katzman R. Education and the prevalence of dementia and Alzheimer's disease. Neurology 1993;43:13-20.

59 Evans DA, Hebert LE, Beckett LA, et al. Education and other measures of socioeconomic status and risk of incident Alzheimers disease in a defined population of older persons. Arch Neurol 1997;54:1399-405.

60 Friedland RP. Epidemiology, education, and the ecology of Alzheimer's disease. Neurology 1993;43:246-9.

61 Mortimer JA, Graves AB. Education and other socioeconomic determinants of dementia and Alzheimer's disease. Neurology 1993;43(suppl 4): S39-44. 